\title{
CeBER
}

CENTRE FOR BUSINESS AND ECONOMICS RESEARCH

UNIVERSITY OF COIMBRA

\section{Robots are not always bad for employment and wages}

\author{
Tiago Miguel Guterres Neves Sequeira
}

University of Coimbra, Centre for Business and Economics Research, CeBER and

Faculty of Economics

\section{Susana Garrido}

University of Coimbra, CeBER - Centre for Business and Economics Research, Faculty of Economics

\author{
Marcelo Serra Santos \\ CeBER
}

CeBER Working Papers

No. 16 / 2020 


\title{
Robots are not always bad for employment and wages*
}

\author{
Tiago Neves Sequeira $^{\dagger} \quad$ Susana Garrido \\ Marcelo Santos \\ CeBER, Faculdade de Economia, Universidade de Coimbra
}

\begin{abstract}
We reassess the impact that robotization has on wages and employment, using a database on US commuting zones from 1990 to 2007. Using an argument based on the transitional dynamics we show that the negative displacement effects of robotization can be surpassed by productivity and reallocation effects, leading to positive effects on employment after a certain level of penetration in industry. In fact, we confirm this effect through regressions that are subject to different robustness checks. Previous evidence according to which robotization always decreases employment and wages are thus not confirmed.
\end{abstract}

JEL classification: J23, J24, O33.

Keywords: Robots, Employment, Fourth Industrial Revolution, Nonlinear effects of robots.

\footnotetext{
*This work has been funded by national funds through FCT - Fundação para a Ciência e a Tecnologia, I.P., Project $\mathrm{UIDB} / 05037 / 2020$.

${ }^{\dagger}$ Corresponding author. Faculdade de Economia, Universidade de Coimbra. Avenida Dias da Silva, 165, Coimbra, Portugal. e-mail: tiago.n.sequeira@fe.uc.pt.
} 


\section{Introduction}

There is a current and rising concern about the effect of robotization in employment in the coming years in both society and academia. Robots "to replace up to 20 million factory jobs" by 2030 is the title of a newspaper article signed by Rory Cellan-Jones on BBC on 26 June 2019.뭄ำ

Although the concern with the replacement of workers by machines in performing tasks in the economy is not new, as John Maynard Keynes and Wassily Leontief have referred to it (see Acemoglu and Restrepo (2019)), since the mid-2010s scholars have been writing about the potential loss of jobs due to automation technologies (e.g., Bryninltsson and McAtee (ख014); Ford (2015)). Literature reports that automation of certain low and medium skilled jobs leads to wage inequality and employment polarization (e.g., Autor et al. (2003); Gons and Manning (2007); Michaels et all (2014)). Michaels et al. (2014) showed that in the US and other OECD countries, industries facing faster growth of ICT also had greater increases in relative demand for highly educated workers and greater falls in relative demand for middle educated workers.

Acemnglu and Restrepn (2019) presented evidence of a negative equilibrium impact of automation technologies on US employment and wages, especially with regard to robots - evidence that has been extended by the same authors for France (Acemoglu et al. (2020)). However, this negative effect of robotization on employment and wages is not consensual and has been subject to discussion in the literature. For example, Graetz and Michaels (2018) use a panel data on robot adoption within industries in 17 countries from 19932007, and new instrumental variables that rely on robots' comparative advantage in specific tasks and show that robots not only increase productivity and reduce low-skilled workers' share but did not significantly reduce total employment. Artuc et al (2018) is concerned with the effects of robotization on the less developed countries, which have not heavily adopted those technologies but have been impacted by their adoption in the more developed countries. They conclude that there is a positive effect of robotization on country production and imports coming from less developed countries. Additionally, they observe the effects of the falling price of robots throughout time. The authors' model illustrates a non-linearity in the relationship between wages and robot prices. As robot adoption occurs in the more technological advanced countries, production in the robotized sector(s) expands, raising demand for the tasks in which robotization is technologically impossible or unrealistic. Eventually, the share of labor in the robotized sector(s) expands, thereby raising overall labor demand and leading to higher employment and wages in the developed countries. These feedback effects can be beyond some positive effects of robotization on employment and wages in certain conditions. Finally, Guimarães and Gil (2019), in a model in which the main concern is to explain the falling share of labor, also concluded that automation-augmenting shocks reduce the labor share but increase employment and wages.

\footnotetext{
${ }^{1}$ https://www.bbc.com/news/business-48760799
} 
In this paper we depart from the model and the evidence in Acemoglu and Restrepo (2019) in such a away that this can be considered a replication exercise with novel results. First, we show that if we take into account transitional dynamics arguments in their model, productivity and composition positive effects of robotization can indeed dominate the negative displacement effect. The idea is that rising cost savings with adoption may imply that productivity and composition effects become greater than the employment displacement at a certain point in time and this reverses the negative influence robotization once had on employment. However, alternative explanations based on the increase in demand for human capital (skilled labor) due to robotization - as claimed by Graetz and Michaels (2018) - could be also considered.

Second and as our main contribution, we show that the linear effect presented in Acemoglu and Restrepo (2019) is not robust to the introduction of a squared term on robots' adoption. In fact, there is compelling evidence of a U-shaped relationship between robotization and employment in the most robust regressions. This means that after a given level of robotization, further increase induces an employment rise. Our contribution is to revisit the Acemoglu and Restrepo (2019) model, highlight some transitional aspects that were not developed by the authors, and find evidence according to which an empirical linear negative effect of robots in employment is not as robust as revealed in that article's findings. Several arguments can be behind a positive effect of robotization on employment and wages. We use the one arising from the productivity effect. Productivity rises and after a certain level leads to higher employment and wages, surpassing the displacing effect robotization can have in the beginning.

In Section 2 we review the Acemoglu and Restrepd (2019) model and introduce the arguments according to which within their model we should believe in a nonlinear relationship between employment (and wages) and robotization. Then in Section 3 we show the regression results in which we argue for that nonlinear relationship. Finally, in Section 4 we conclude.

\section{The Model}

The model is the same as in Acemoglu and Restrepo (2019). In order for the paper to be self-contained we briefly present the model and the crucial derivations for the equilibrium and our different analysis.

\subsection{Setup}

The economy is made up of of $|\mathcal{C}|$ commuting zones, each one denoted as $c \in \mathcal{C}$. Each commuting zone has preferences pertaining to an aggregate of the output of $|\mathcal{I}|$ industries, which are given as 


$$
Y_{c}=\left(\sum_{i \in \mathcal{I}} \nu_{i}^{\frac{1}{\sigma}} Y_{c i}^{\frac{\sigma-1}{\sigma}}\right)^{\frac{\sigma}{\sigma-1}}
$$

where $\sigma>0$ denotes the elasticity of substitution across goods produced by different industries and the $\nu_{i}$ 's are share parameters. Those are shares of industry $i$ output in the consumption aggregate (with $\left.\sum_{i \in \mathcal{I}} \nu_{i}=1\right)$. In the autarky equilibrium a commuting zone consumes all of the goods it produces, denoted by $X_{c i}$. Hence, for all $i \in \mathcal{I}$ and $c \in \mathcal{C}$, we have $Y_{c i}=X_{c i}{ }^{\square}$ Each industry produces output by combining capital with a continuum of tasks indexed by $s \in[0,1]$. Each task can be performed by using industrial robots or human labor. Denote $x_{c i}(s)$ the quantity of task $s$ utilized in the production of $X_{c i}$. These tasks must be combined in fixed proportions such that the aggregate production is:

$$
X_{c i}=\alpha^{-\alpha}(1-\alpha)^{-(1-\alpha)} A_{c i}\left[\min _{s \in[0,1]}\left\{x_{c i}(s)\right\}\right]^{\alpha} K_{c i}^{1-\alpha}
$$

where $K_{c i}$ is the non-robot capital in use in industry $i, 1-\alpha$ is the share of non-robot capital in the production process, $A_{c i}$ is the industry's productivity $i$, and the term $\alpha^{-\alpha}(1-\alpha)^{-(1-\alpha)}$ is a convenient normalization. Differences in the $A_{c i}$ 's become different compositions of employment among the various commuting zones. Some workers come to be replaced by industrial robots in some or all of their tasks. Specifically, without loss of generalization, we assume that in industry $i$, tasks $\left[0, \theta_{i}\right]$ are technologically automated and can be performed by robots. Moreover, there is the same $\theta_{i}$ in industry $i$, meaning that the same technology is available to all commuting zones. Denoting the productivity of labor by $\gamma_{L}$ and the productivity of robots by $\gamma_{M}>0$, we have the quantity of task $s$ used in the aggregate production:

$$
x_{c i}(s)=\left\{\begin{array}{cc}
\gamma_{M} M_{c i}(s)+\gamma_{L} L_{c i}(s) & \text { if } s \leq \theta_{i} \\
\gamma_{L} L_{c i}(s) & \text { if } s>\theta_{i}
\end{array}\right.
$$

where $L_{c i}(s)$ and $M_{c i}(s)$ are the numbers of workers and robots, respectively, performing task $s$. Note that due to the fact that tasks above $\theta_{i}$ have not yet been attributed to robots, they must be performed by human workers.

In each commuting zone $c$ human labor is provided by a representative household having preferences over consumption $C_{c}$ and labor $L_{c}$ :

$$
\frac{C_{c}^{1-\psi}-1}{1-\psi}-\frac{B}{1+\varepsilon} L_{c}^{1+\varepsilon}
$$

\footnotetext{
${ }^{2}$ The consumption aggregate in each commuting zone is numeraire (with price normalized to 1 ) and denote the price of the output of industry i in commuting zone $c$ by $P_{c i}^{X}$.
} 
subject to a budget constraint represented by $C_{c} \leq W_{c} L_{c}+\Pi_{c}$, where $\Pi_{c}$ is non-labor (capital and profit) income. In this specification, the income elasticity of labor supply is determined by $\psi$, and $\varepsilon$ is the inverse of the Frisch elasticity of human labor supply. Robots are installed using investment (in units of the final good), denoted by $I_{c}$, with the production function $M_{c}=D(1+\eta) I_{c}^{\frac{1}{1+\eta}}$, and have a rental price of $R_{c}^{M}$.. Finally, in the autarky model we fix the supply of capital in commuting zone $c$ at $K_{c}$, and denote its price by $R_{c}^{K}$.

\subsection{Equilibrium}

An equilibrium is a set of prices $\left\{W_{c}, R_{c}^{M}, R_{c}^{K}\right\}_{c \in \mathcal{C}}$ and quantities $\left\{C_{c}, Y_{c}, I_{c}, L_{c}, M_{c}\right\}_{c \in \mathcal{C}}$ such that in all commuting zones, firms maximize profits, households maximize their utility, and the markets for capital, labor, robots, and final goods clear such that:

$$
\sum_{i \in \mathcal{I}} \int_{[0,1]} L_{c i}(s)=L_{c}, \quad \sum_{i \in \mathcal{I}} \int_{[0,1]} M_{c i}(s)=M_{c}, \quad \sum_{i \in \mathcal{I}} K_{c i}(s)=K_{c}, \quad C_{c}=Y_{c}-I_{c} .
$$

To examine the equilibrium impact of robots, cost savings derived from the use of robots in commuting zone $c$ should be defined as:

$$
\pi_{c}=1-\frac{\gamma_{L}}{\gamma_{M}} \frac{R_{c}^{M}}{W^{c}}
$$

Robots are not adopted when $\pi_{c}<0$; we focus below on the case in which $\pi_{c}>0$ in all commuting zones. The next steps characterize the partial equilibrium impact of an advance in automation/robotics technology for industry $i$, denoted by $d \theta_{i}$.

The first-order condition for the representative household in commuting zone $c$ is

$$
W_{c}=B C_{c}^{\psi} L_{c}^{\varepsilon}
$$

Market clearing implies

$$
\begin{aligned}
C_{c} & =Y_{c}-I_{c} \\
& =Y_{c}-D^{-1-\eta}(1+\eta)^{-1-\eta} M_{c}^{1+\eta}
\end{aligned}
$$

\footnotetext{
${ }^{3}$ This formulation, with $\eta>0$, allows the supply of robot services to a commuting zone to be upward sloping. This is reasonable in the medium term, since about two thirds of the costs of robots are for services supplied by local, specialized robot integrators that install, program, and maintain this equipment (Leigh and Kraft (018)).
} 
where the second line follows by inverting the production function for robots, $M_{c}=D(1+\eta) I_{c}^{\frac{1}{1+\eta}}$ introduced above. Combining this with (4), we obtain

$$
W_{c}=B\left(Y_{c}-D^{-1-\eta}(1+\eta)^{-1-\eta} M_{c}^{1+\eta}\right)^{\psi} L_{c}^{\varepsilon}
$$

From the production function for robots we also have

$$
R_{c}^{M}=D^{-1-\eta}(1+\eta)^{-\eta} M_{c}^{\eta}
$$

Recall that in the autarky model the supply of capital in commuting zone $c$ is taken to be exogenously given at $K_{c}>0$.

As we assume that $\pi_{c}>0$ in all commuting zones, tasks below $\theta_{i}$ are produced with robots at a $\operatorname{cost} \frac{R_{c}^{M}}{\gamma_{M}}$ and tasks above $\theta_{i}$ are produced with labor at a $\operatorname{cost} \frac{W_{c}}{\gamma_{L}}$. As a result, the marginal cost - and thus the price - of industry $i$ is

$$
P_{c i}^{X}=\frac{1}{A_{c i}}\left(\theta_{i} \frac{R_{M}^{K}}{\gamma_{M}}+\left(1-\theta_{i}\right) \frac{W_{c}}{\gamma_{L}}\right)^{\alpha} R_{c}^{K^{1-\alpha}}
$$

Next, the share of labor in production tasks in industry $i$ is

$$
s_{c i}^{L}=\frac{W_{c} L_{c i}}{\alpha P_{c i}^{X} X_{c i}}=\frac{\left(1-\theta_{i}\right) \frac{W_{c}}{\gamma_{L}}}{\theta_{i} \frac{R_{M}^{K}}{\gamma_{M}}+\left(1-\theta_{i}\right) \frac{W_{c}}{\gamma_{L}}}
$$

Note that a fraction $1-\alpha$ of the total costs of the sector are paid to capital (given the Cobb-Douglas technology in (2)), and $s_{c i}^{L}$ is the share of labor in the remainder. Therefore the share of labor in the value added of industry $i$ is just $\alpha s_{c i}^{L}$.

As the final good in each commuting zone is the numeraire, we also have the following ideal price index condition, $1=\sum_{i \in \mathcal{I}} \nu_{i} P_{c i}^{X^{1-\sigma}}$. Combining (8) and (9), the wage bill in commuting zone $c$ becomes

$$
W_{c} L_{c}=\sum_{i \in \mathcal{I}} W_{c} L_{c i}=\sum_{i \in \mathcal{I}} \alpha s_{c i}^{L} P_{c i}^{X} X_{c i}
$$

From equation (1), the demand for industry $i$ in commuting zone $c$ is $X_{c i}=\nu_{i} P_{c i}^{X-\sigma} Y_{c}$, and substituting for this, the previous expression is rewritten as

$$
W_{c} L_{c}=\sum_{i \in \mathcal{I}} \alpha s_{c i}^{L} \nu_{i} P_{c i}^{X^{1-\sigma}} Y_{c}
$$


In the same way, the demand for robots and capital is expressed respectively as:

$$
\begin{gathered}
R_{c}^{M} M_{c}=\sum_{i \in \mathcal{I}} \alpha\left(1-s_{c i}^{L}\right) \nu_{i} P_{c i}^{X^{1-\sigma}} Y_{c} \\
R_{c}^{K} K_{c}=(1-\alpha) Y_{c}
\end{gathered}
$$

The autarky equilibrium is a competitive equilibrium in an economy with a representative household. Therefore, from the second welfare theorem any autarky equilibrium is a solution to the maximization of the utility of the representative household subject to the technology and feasibility constraints. This problem is expressed in Appendix. Since the labor share in industry $i$ is $\alpha s_{c i}^{L}$ and the value added of this industry is $\nu_{i} P_{c i}^{X^{1-\sigma}} Y_{c}$, we have

$$
W_{c} L_{c i}=s_{c i}^{L} \alpha \nu_{i} P_{c i}^{X^{1-\sigma}} Y_{c}
$$

Using the formulas for $s_{c i}^{L}$ and $P_{c i}^{X}$ in equations (8) and (9), we obtain

$$
\begin{aligned}
W_{c} L_{c i} & =\frac{\left(1-\theta_{i}\right) \frac{W_{c}}{\gamma_{L}}}{\theta_{i} \frac{R_{M}^{K}}{\gamma_{M}}+\left(1-\theta_{i}\right) \frac{W_{c}}{\gamma_{L}}} \alpha \nu_{i} P_{c i}^{X^{1-\sigma}} Y_{c} \\
& =\frac{\left(1-\theta_{i}\right) \frac{W}{\gamma_{L}}}{\left(A_{c i} P_{c i}^{X}\right)^{\frac{1}{\alpha}}} R_{c}^{K} \frac{1-\alpha}{\alpha} \alpha \nu_{i} P_{c i}^{X^{1-\sigma}} Y_{c} \\
& =\frac{\left(1-\theta_{i}\right) \frac{W}{\gamma_{L}}}{\left(A_{c i} P_{c i}^{X}\right)^{\frac{1}{\alpha}}}\left((1-\alpha) \frac{Y_{c}}{K_{c}}\right)^{\frac{1-\alpha}{\alpha}} \alpha \nu_{i} P_{c i}^{X^{1-\sigma}} Y_{c}
\end{aligned}
$$

where in the last line we used the fact that $R_{c}^{K}=(1-\alpha) \frac{Y_{c}}{K_{c}}$. Simplifying this expression yields

$$
L_{c i}=\left(1-\theta_{i}\right) \frac{\alpha(1-\alpha)^{\frac{1-\alpha}{\alpha}} \nu_{i}}{\gamma_{L} A_{c i}^{\frac{1}{\alpha}}} P_{c i}^{X^{1-\sigma-\frac{1}{\alpha}}} Y_{c}^{\frac{1}{\alpha}} K_{c}^{\frac{\alpha-1}{\alpha}}
$$

Taking logs on both sides and differentiating yields the following:

$$
d \ln L_{c}=-\sum_{i \in \mathcal{I}} \ell_{c i} \frac{d \theta_{i}}{1-\theta_{i}}+\frac{1}{\alpha} d \ln Y_{c}-\left(\sigma+\frac{1}{\alpha}-1\right) \sum_{i \in \mathcal{I}}\left(\ell_{c i}-\chi_{c i}\right) d \ln P_{c i}^{X}
$$

where $\ell_{c i}$ represents the industry's share in total employment in commuting zone $c$, while $\chi_{c i}$ is this industry's share of value added in the local economy. In equation (四), the first two terms are the displacement and productivity effects, respectively. The third term shows that the impact of the composition effect for labor demand depends on whether automation is reallocating output toward sectors that are more labor intensive than average (those for which $\ell_{c i}>\chi_{c i}$ ). This composition effect disappears when all industries have the same labor share. Aggregating over industries yields: 


$$
d \ln L_{c i}=-\frac{d \theta_{i}}{1-\theta_{i}}+\frac{1}{\alpha} d \ln Y_{c}-\left(\sigma+\frac{1}{\alpha}-1\right) d \ln P_{c i}^{X}
$$

Equation (116) provides a partial equilibrium characterization of how the demand for labor changes following automation. Note that $d \ln L c j=d \ln Y c$ for industries $j$ that are not undergoing any automation. Thus, for industries $i$ that undergo automation $d \ln L c i<d \ln L c j$ if :

$$
\left(\sigma-1+\frac{1}{\alpha}\right) d \ln P_{c i}<\frac{d \theta_{i}}{1-\theta_{i}} \Longleftrightarrow\left(\sigma-1+\frac{1}{\alpha}\right) \alpha \pi_{c} s_{c i}^{L} \frac{d \theta_{i}}{1-\theta_{i}}<\frac{d \theta_{i}}{1-\theta_{i}} \Longleftrightarrow \pi_{c} s_{c i}^{L}<\frac{1 / \alpha}{\left(\sigma-1+\frac{1}{\alpha}\right)}
$$

where we must use the $\log$ differentiation of prices in equation ( $\mathbf{(})$ and the expressions for profits - equation (3) - and shares - equation (91). We remember that $\pi_{c}$ is the cost savings from using robots in commuting zone c; $s_{i c}^{L}$ is the industry's labor share in production tasks; $\sigma>0$ denotes the elasticity of substitution across goods produced by different industries, and $\alpha$ is the share of robots in production (see equation (四)). This means that equation 17 gives a sufficient condition for the displacement effect to prevail over the other forces and reduce (relative) industry employment. However, Acemnglu and Restrepn ([019) focus on comparative statics and ignore potential dynamic effects, which we analyze below.

\subsection{Argument for a nonlinear effect of robotization}

There is compelling evidence according to which the prices of Robots $\left(R_{c}^{M}\right)$ are falling and wages $\left(W^{c}\right)$ are rising (see e.g. empirical evidence in Artuc et al. (2018)). When robots are not adopted $\left(\pi_{c}<0\right)$, if the productivity of robots is rising more than the productivity of labor such that $\frac{\gamma_{L}}{\gamma_{M}}$ is declining, then eventually, robots will be adopted in a certain zone where they previously were not used. Then even when robots begin to be adopted $\left(\pi_{c}>0\right)$, this trend will continue and the costs savings of adopting robots will continue to rise. Can this trend reverse the condition in (미)? Yes! With a rising $\pi_{c}>0$ it becomes evident that the inequality in (17) can be reversed and that employment can thus rise with robotization after a certain level of robots' penetration.

\section{$3 \quad$ Empirical Evidence}

In this Section we describe the data and the sources as well as the main empirical results. ${ }^{\text {a }}$

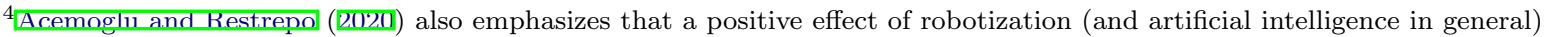
is dependent on the strength of the productivity effect.

${ }^{5}$ In order to increase comparability between our results and those of Aremnolu and Restreno (2019) and other than the nonlinear specification introduced by us, we strictly follow the different specifications in those authors' paper.
} 
Table 1: Descriptive Statistics

\begin{tabular}{llllll}
\hline \multicolumn{7}{c}{ 1+Main Exposure } \\
\hline & Obs & Mean & SD & Min & Max \\
Employment baseline & 722 & 2.626807 & 1.041086 & 1.3522772 & 10.0353 \\
Wages baseline & 180500 & 2.626807 & 1.040368 & 1.3522772 & 10.0353 \\
Employment stacked dif & 1444 & 1.8134036 & 0.65194 & 1.10148 & 8.616601 \\
Wages stacked diff & 361000 & 1.813404 & 0.6517152 & 1.10148 & 8.616601 \\
\hline \multicolumn{7}{c}{$(1+\text { Main Exposure })^{2}$} \\
\hline \multirow{2}{*}{ Employment baseline } & 722 & Mean & SD & Min & Max \\
Wages baseline & 180500 & 7.982474 & 8.575732 & 1.828654 & 100.7072 \\
Employment stacked diff & 1444 & 3.713164 & 8.569815 & 1.828654 & 100.7072 \\
Wages stacked diff & 361000 & 3.713164 & 4.110466 & 1.213258 & 74.24581 \\
\hline
\end{tabular}

\subsection{Data}

Our database is that of Acemnglu and Restrepn (2019) and is available online from the authors. ${ }^{\text {[ }}$ [CARACTERIZAR DADOS] As becomes clear from their exposure to robots measure ( $A P R$ in their equation 11) and the data in the paper they assume values between 0 and nearly 9 in that variable. To avoid the non-monotony of the squared function in the subdomain $[0,1]$ we consider the monotonous transformation of $A P R$ :

$$
A P R^{*}=(1+A P R)
$$

Thus, our measure of exposure to robots is always one plus the measure in Acemnglu and Restrepn (2010). In order to test for the empirical nonlinear effect of exposure to robots in the regressions presented by Acemoglu and Restrepo (2019), instead of the $A P R$ variable, we use both $A P R^{*}$ and $A P R^{* 2}$. As in Acemnglu and Restrepo (2019), we use different samples to run our regressions. First, we focus on the 722 commuting zones that comprise the US continental territory (Tolbert and Sizer (1996)), for which we ran regressions that explain the relationship between robotization and employment. For hourly wages we have industry data that raise the sample to 87,100 (see Table 1). Those samples double when using stacked differences between two different periods.

\subsection{Results}

Each of the regressions includes a set of controls that are specified under the table (also in the following tables) such as census divisions, demographics (log population; the share of females; the share of population older than 65 years; the shares of population that did not attend college, attended some college, have undergraduate

\footnotetext{
${ }^{6}$ https://economics.mit.edu/faculty/acemoglu/data/robotsjobs
} 
and/or professional degrees, and masters and doctoral degrees; and the shares of Whites, Blacks, Hispanics, and Asians), industry shares (shares of employment in manufacturing and light manufacturing, the female share of manufacturing employment in 1990), trade (exposure to Chinese imports), the share of employment in routine jobs, commuting zones fixed effects, and time period dummies. ${ }^{\mathbb{1}}$ In each table, when both the linear effect and the quadratic effect are significant we present the minimizer of the quadratic function, i.e., the value of exposure to robots above which a rise in employment and/or wages is expected according to the regressions. This value is in italics if it is less than the maximum observed. This should indicate that this is not only a prediction from estimations (which is out-of-the-sample) but should be already happening as it is on-the-sample.

Table 2 presents the baseline results of regressions for employment and hourly wages for the entire period between 1990 and 2007. Panel A presents long-differences estimates for changes in the employment to population ratio. Panel B presents similar estimates for changes in log hourly wages. The specifications in Panel B are estimated at the demographic cell commuting zone level, in which age, gender, education, and race define the demographic cells. This is a procedure common to all regressions in which the dependent variable is the wage (which are presented in panel B in each of the following Tables). The first five columns report regressions weighted by population in 1990. Column 5 shows results excluding the top one percent of commuting zones with the greatest exposure to robots. Column 6 presents unweighted regressions. In that table results indicate that only for employment in columns (1) and (2) is a non-linear quadratic relationship is observed. In this relationship the threshold value of exposure to robots above which a rise in employment may be observed is about 9 which is within the observed sample (which has a maximum of 10.035).

In Table 3 we change to stacked differences. Panel A report stacked-differences estimates for changes in the employment to population ratio, 1990-2000 and 2000-2007 and Panel B report similar estimates but for changes in log hourly wages, 1990-2000 and 2000-2007. As in Table 2, the specifications in Panel B are estimated at the level of the demographic cell commuting zone. Columns 1-5 and 7 report regressions weighted by population in 1990. Column 5 has results excluding the top one percent of commuting zones with the highest exposure to robots. Columns 6 and 8 greatest unweighted regressions.

Results now yield quite a different picture. Regressions in columns 1, 2, 6 to 8 (for regressions for employment) and in columns 7 and 8 (for regressions for wages) present nonlinear significant coefficients, meaning that the effect of exposure to robots tends to be diminishing as robotization increases, and in certain cases the effect of exposure to robots may even be positive. Note that some of these results happen in the regressions in which more controls are introduced. In particular for the regressions in columns 6 and 8 for

\footnotetext{
${ }^{7}$ For ease of comparison, we follow exactly the same specifications as in Acemoglu and Restrepo (2019) except for the introduction of the quadratic term.
} 
Table 2: The effects of robots on employment and wages: long differences

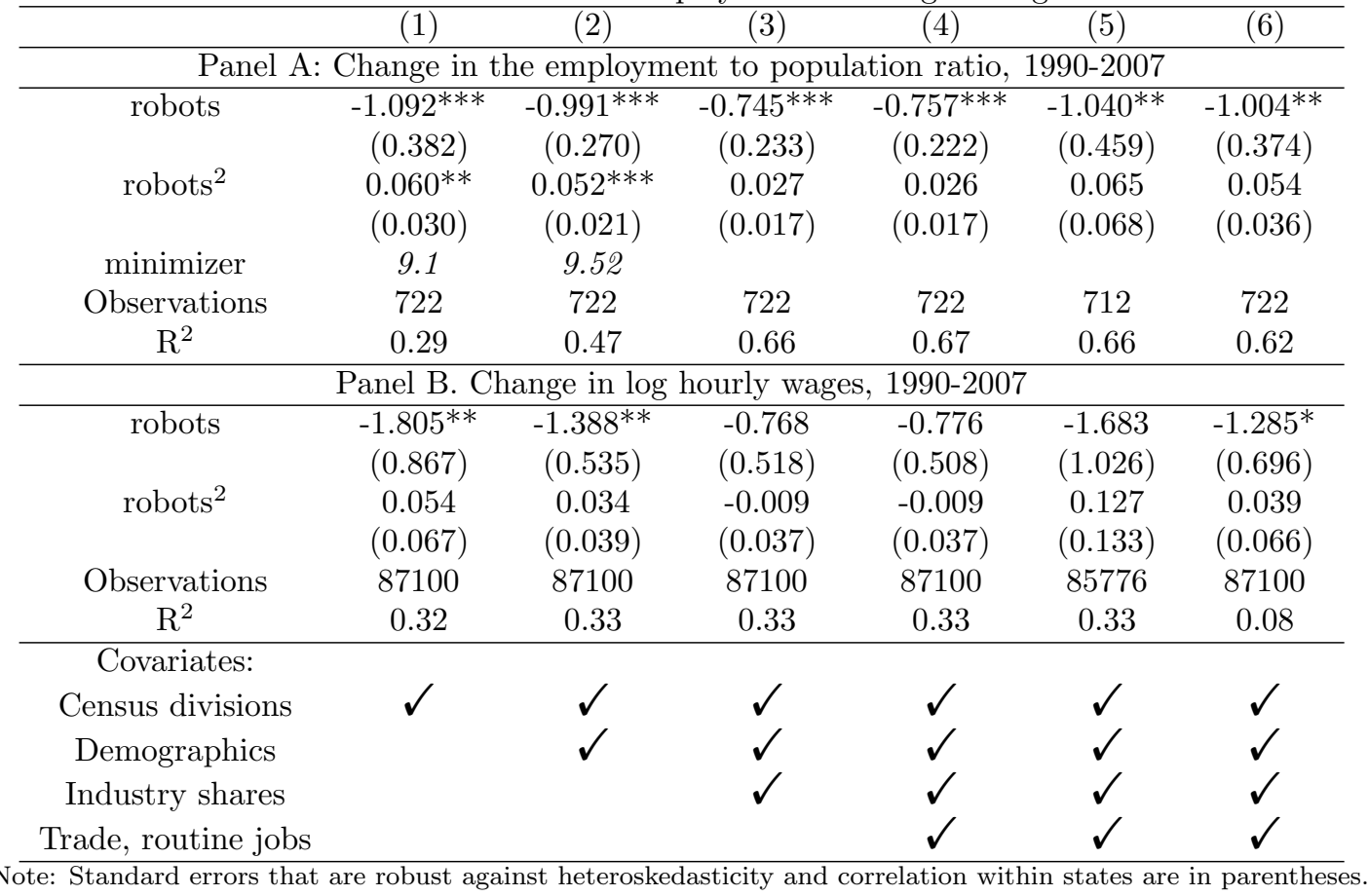

employment and 7 and 8 for wages there is a threshold level of robotization above which employment and wages may rise with more use of robots in industry.

In Table 4 we separate robotization in the Automotive industry (the one with the highest level of robots penetration) from the other industries. In that Table, columns 1-3 report long-differences estimates for the 1990-2007 period. Columns 4-6 report stacked-differences estimates for the 1990-2000 and 2000-2007 periods. Columns 1-2 and 4-5 report regressions weighted by population in 1990. Columns 3 and 6 report unweighted regressions.

While the maximum exposure to robots in the automotive industry is 8.89 , in other industries the maximum is 6.31 . We included the quadratic terms for both industries. It is remarkable that for most robust regressions and robot exposure in the automotive industry, there is a nonlinear relationship that indicates a positive effect of robotization on employment and wages after a certain level of robotization that is within the sample, i.e., that the data indicate that it should already be seen. When looking at the ceteris paribus effect of other industries' robotization, the same happens and for much lower levels of robotization. For example, we may verify a positive effect of robotization on wages after a robotization exposure level of 2.7 (in column 8), which is slightly over the mean of robotization for those industries.

In Table 5 we test the robustness of our specification to the introduction of capital, IT capital, and industry added value. Columns 1-2 and 5-6 report long-differences estimates for 1990-2007. Columns 3-4 
Table 3: The effects of robots on employment and wages: stacked differences

\begin{tabular}{|c|c|c|c|c|c|c|c|c|}
\hline & $(1)$ & $(2)$ & $(3)$ & $(4)$ & $(5)$ & $(6)$ & $(7)$ & $(8)$ \\
\hline \multicolumn{9}{|c|}{ Panel A: Change in the employment/population, 1990-2007 and 2000-2007 } \\
\hline robots & $\begin{array}{c}-1.000^{* * *} \\
(0.270)\end{array}$ & $\begin{array}{c}-1.064^{* * *} \\
(0.254)\end{array}$ & $\begin{array}{c}-0.835^{* * *} \\
(0.264)\end{array}$ & $\begin{array}{c}-0.750^{* * *} \\
(0.256)\end{array}$ & $\begin{array}{l}-0.230 \\
(0.432)\end{array}$ & $\begin{array}{c}-1.286^{* * *} \\
(0.278)\end{array}$ & $\begin{array}{c}-1.041^{* * *} \\
(0.364)\end{array}$ & $\begin{array}{c}-1.932^{* * *} \\
(0.413)\end{array}$ \\
\hline robots $^{2}$ & $\begin{array}{l}0.041^{*} \\
(0.023)\end{array}$ & $\begin{array}{l}0.051^{* *} \\
(0.022)\end{array}$ & $\begin{array}{c}0.033 \\
(0.023)\end{array}$ & $\begin{array}{c}0.021 \\
(0.023)\end{array}$ & $\begin{array}{l}-0.085 \\
(0.082)\end{array}$ & $\begin{array}{c}0.078^{* *} \\
(0.033)\end{array}$ & $\begin{array}{l}0.051^{*} \\
(0.030)\end{array}$ & $\begin{array}{c}0.118^{* * *} \\
(0.041)\end{array}$ \\
\hline minimizer & 12.2 & 10.43 & - & - & - & 8.24 & 10.2 & 8.19 \\
\hline Obs. & 1444 & 1444 & 1444 & 1444 & 1424 & 1444 & 1444 & 1444 \\
\hline $\mathrm{R}^{2}$ & 0.25 & 0.33 & 0.39 & 0.41 & 0.40 & 0.40 & 0.71 & 0.44 \\
\hline \multicolumn{9}{|c|}{ Panel B. Change in log hourly wages, 1990-2007 and 2000-2007 } \\
\hline robots & $\begin{array}{l}-2.212^{* *} \\
(0.902)\end{array}$ & $\begin{array}{c}-2.098^{* *} \\
(0.974)\end{array}$ & $\begin{array}{l}-1.747 \\
(1.055)\end{array}$ & $\begin{array}{l}-1.539 \\
(1.013)\end{array}$ & $\begin{array}{c}0.087 \\
(1.670)\end{array}$ & $\begin{array}{c}-2.416^{* *} \\
(0.927)\end{array}$ & $\begin{array}{c}-4.043^{* * *} \\
(1.180)\end{array}$ & $\begin{array}{c}-4.911^{* * *} \\
(1.323)\end{array}$ \\
\hline robots $^{2}$ & $\begin{array}{c}0.074 \\
(0.081)\end{array}$ & $\begin{array}{c}0.064 \\
(0.088)\end{array}$ & $\begin{array}{c}0.036 \\
(0.094)\end{array}$ & $\begin{array}{c}0.010 \\
(0.092)\end{array}$ & $\begin{array}{l}-0.311 \\
(0.241)\end{array}$ & $\begin{array}{c}0.105 \\
(0.097)\end{array}$ & $\begin{array}{l}0.231^{* *} \\
(0.103)\end{array}$ & $\begin{array}{l}0.286^{* *} \\
(0.127)\end{array}$ \\
\hline minimizer & - & - & - & - & - & - & 8.75 & 8.58 \\
\hline Obs. & 183606 & 183606 & 183606 & 183606 & 180818 & 183606 & 183606 & 183606 \\
\hline $\mathrm{R}^{2}$ & 0.28 & 0.28 & 0.28 & 0.29 & 0.27 & 0.09 & 0.32 & 0.10 \\
\hline Covariates: & & & & & & & & \\
\hline $\begin{array}{l}\text { Time period dum- } \\
\text { mies }\end{array}$ & $\sqrt{ }$ & $\sqrt{ }$ & $\sqrt{ }$ & $\checkmark$ & $\sqrt{ }$ & $\sqrt{ }$ & $\checkmark$ & $\sqrt{ }$ \\
\hline Census divisions & $\sqrt{ }$ & $\sqrt{ }$ & $\sqrt{ }$ & $\sqrt{ }$ & $\sqrt{ }$ & $\sqrt{ }$ & $\sqrt{ }$ & $\sqrt{ }$ \\
\hline Demographics & & $\sqrt{ }$ & $\sqrt{ }$ & $\sqrt{ }$ & $\sqrt{ }$ & $\sqrt{ }$ & $\sqrt{ }$ & $\sqrt{ }$ \\
\hline Industry shares & & & $\sqrt{ }$ & $\sqrt{ }$ & $\sqrt{ }$ & $\sqrt{ }$ & $\sqrt{ }$ & $\sqrt{ }$ \\
\hline Trade, routine jobs & & & & $\checkmark$ & $\checkmark$ & $\checkmark$ & $\checkmark$ & $\checkmark$ \\
\hline $\begin{array}{l}\text { Commuting zone } \\
\text { trends }\end{array}$ & & & & & & & $\sqrt{ }$ & $\sqrt{ }$ \\
\hline
\end{tabular}


Table 4: The effects of robots on employment and wages: the role of the automotive industry

\begin{tabular}{|c|c|c|c|c|c|c|}
\hline & $(1)$ & $(2)$ & $(3)$ & $(4)$ & $(5)$ & $(6)$ \\
\hline \multicolumn{7}{|c|}{ Panel A. Change in the employment to population ratio } \\
\hline robots & $\begin{array}{c}-0.990^{*} \\
(0.586)\end{array}$ & $\begin{array}{c}-1.025^{* *} \\
(0.384)\end{array}$ & $\begin{array}{c}-1.117^{* *} \\
(0.451)\end{array}$ & $\begin{array}{c}-1.538^{* * *} \\
(0.408)\end{array}$ & $\begin{array}{c}-1.341^{* * *} \\
(0.287)\end{array}$ & $\begin{array}{c}-1.858^{* * *} \\
(0.356)\end{array}$ \\
\hline \multirow[t]{2}{*}{ robots $^{2}$} & 0.056 & 0.056 & $0.068^{*}$ & $0.109^{* *}$ & $0.091^{* * *}$ & $0.161^{* * *}$ \\
\hline & $(0.055)$ & $(0.036)$ & $(0.040)$ & $(0.043)$ & $(0.031)$ & $(0.037)$ \\
\hline minimizer & - & - & 8.21 & 7.06 & 7.37 & 5.77 \\
\hline \multirow[t]{2}{*}{ robots in o. industries } & $-2.889^{* * *}$ & $-0.982^{*}$ & $-1.521^{*}$ & $-3.590 * * *$ & $-1.941^{*}$ & $-2.914^{* *}$ \\
\hline & $(0.931)$ & $(0.510)$ & $(0.853)$ & $(1.210)$ & $(0.973)$ & $(1.094)$ \\
\hline \multirow[t]{2}{*}{ robots in o. industries ${ }^{2}$} & $0.412^{* * *}$ & 0.104 & 0.181 & $0.765^{* * *}$ & 0.386 & $0.576^{* *}$ \\
\hline & $(0.140)$ & $(0.076)$ & $(0.128)$ & $(0.282)$ & $(0.234)$ & $(0.248)$ \\
\hline minimizer & 3.51 & - & - & 2.35 & - & 2.53 \\
\hline Obs. & 722 & 722 & 722 & 1444 & 1444 & 1444 \\
\hline \multirow[t]{2}{*}{$\mathrm{R}^{2}$} & 0.31 & 0.67 & 0.62 & 0.26 & 0.42 & 0.40 \\
\hline & Panel I & . Change $\mathrm{i}$ & $\log$ hourly & wages & & \\
\hline \multirow[t]{2}{*}{ robots } & $-1.630^{* *}$ & $-1.121^{* *}$ & -0.669 & $-2.992^{* * *}$ & $-2.933^{* * *}$ & $-3.684^{* * *}$ \\
\hline & $(0.613)$ & $(0.521)$ & $(0.690)$ & $(0.714)$ & $(0.664)$ & $(1.028)$ \\
\hline \multirow[t]{2}{*}{ robots $^{2}$} & 0.041 & 0.018 & -0.042 & $0.176^{* *}$ & $0.170^{* *}$ & $0.284^{* * *}$ \\
\hline & $(0.059)$ & $(0.052)$ & $(0.068)$ & $(0.074)$ & $(0.070)$ & $(0.103)$ \\
\hline minimizer & - & - & - & 8.5 & 8.63 & 6.49 \\
\hline \multirow[t]{2}{*}{ robots in o. industries } & $-4.661^{* *}$ & $-2.155^{*}$ & $-3.518^{* * *}$ & $-5.480^{* *}$ & -2.525 & $-5.571^{* * *}$ \\
\hline & $(1.801)$ & $(1.076)$ & $(1.234)$ & $(2.693)$ & $(2.803)$ & $(2.040)$ \\
\hline \multirow[t]{2}{*}{ robots in o. industries ${ }^{2}$} & $0.572^{* *}$ & 0.231 & $0.415^{* *}$ & 0.986 & 0.378 & $1.032^{* *}$ \\
\hline & $(0.241)$ & $(0.148)$ & $(0.182)$ & $(0.624)$ & $(0.634)$ & $(0.452)$ \\
\hline minimizer & 4.07 & - & 4.24 & - & - & 2.70 \\
\hline Observations & 87100 & 87100 & 87100 & 183606 & 183606 & 183606 \\
\hline $\mathrm{R}^{2}$ & 0.32 & 0.33 & 0.08 & 0.28 & 0.29 & 0.09 \\
\hline \multicolumn{7}{|l|}{ Covariates: } \\
\hline \multicolumn{7}{|l|}{ Time period dummies } \\
\hline Census divisions & $\sqrt{ }$ & $\sqrt{ }$ & $\sqrt{ }$ & $\sqrt{ }$ & $\sqrt{ }$ & $\sqrt{ }$ \\
\hline Baseline covariates & & $\sqrt{ }$ & $\sqrt{ }$ & & $\sqrt{ }$ & $\sqrt{ }$ \\
\hline
\end{tabular}


and 7-8 report stacked-differences estimates for 1990-2000 and 2000-2007. Columns 1-4 report results for employment to population ratio. Columns 5-8 have the results for log hourly wages. Odd-numbered columns report regressions weighted by population in 1990. Even-numbered columns show unweighted regressions. In Panel A we control for a measure of exposure to capital by interacting the increase in log capital in each industry with its baseline employment share in the commuting zone. In panel B we control for a measure of exposure to IT capital by interacting the increase in log IT capital in each industry with its baseline employment share in the commuting zone. In panel $\mathrm{C}$ we control for a measure of exposure to industry value added by interacting the increase in log value added in each industry (between 1992 and 2007 in all models) with its baseline employment share in the commuting zone. Even with all of these additional controls we reach different results. While in some regressions (Panels A and B, columns 5, 6, and 7, and Panel C, column 6) the robotization variable comes out to be non-significant (both the linear and quadratic term), in some others the linear negative relationship becomes the only that is significant (Panel A, column 8; Panel B, columns 2, 3, and 8; Panel C, columns 2, 3, 6, and 8) with a non-significant quadratic coefficient, and in some others there is a significant U-shaped relationship between robotization and employment and/or wages (Panel A, columns 1, 2, 3, and 4; Panels B and C, columns 1 and 4). This means that taking into account the controls for capital and added value the U-shaped relationship is significant between robotization and employment but not between robotization and wages.

Finally, Table 6 shows IV regressions of the effects of exposure to robots on employment and wages for different time periods. Panels A and B have the results for 1990-2007. Panel C has results for 1990-2014, Panel D for 2000-2007, and Panel E for 2000-2014. In all models, we instrument the US exposure to robots using exposure to robots from Denmark, Finland, France, Italy, and Sweden, that is, countries ahead of the United States in robotics excluding Germany, named as EURO5 by Acemoglu and Restrepo (2019). In Panels A, C, D, and E we rescale the US exposure to robots to match the time period used. In Panel B we use an alternative imputation strategy for US exposure to robots described in Acemoglu and Restrepo (2019). Columns 1-3 report results for the employment to population ratio. Columns 4-6 have results for log hourly wages. All IV estimates are from regressions weighted by population in 1990. With this strategy we (and also Acemoglu and Restrepn (2019)) are confident that we control for endogeneity problems such as reverse causality from high employment share (and costs) and robotization.

Results show a clear U-shaped relationship pattern between robotization and employment and/or wages, meaning at least that the negative effect of robotization decreases (become less negative) as robotization increases. This is shown in all regressions in Panels A and B and all but one regressions in panel C, in two regressions in panel D, and four in panel E. Note that panel E extends the period from 2007 ro 2014 . It is also interesting to note that while in Panels $\mathrm{A}, \mathrm{B}$, and $\mathrm{C}$ we can only say that the effect of robotization 
Table 5: The effects of robots controlling for capital deepening, IT capital, and value added

\begin{tabular}{|c|c|c|c|c|c|c|c|c|}
\hline & $(1)$ & $(2)$ & $(3)$ & $(4)$ & $(5)$ & $(6)$ & $(7)$ & $(8)$ \\
\hline \multicolumn{9}{|c|}{ Panel A. Estimates controlling for exposure to capital } \\
\hline \multirow[t]{2}{*}{ robots } & $-0.827^{* * *}$ & $-1.062^{* * *}$ & $-0.912^{* * *}$ & $-1.013^{* * *}$ & -0.285 & -0.652 & -1.470 & $-1.814^{* *}$ \\
\hline & $(0.234)$ & $(0.343)$ & $(0.223)$ & $(0.244)$ & $(0.505)$ & $(0.658)$ & $(0.943)$ & $(0.834)$ \\
\hline \multirow[t]{2}{*}{ robots $^{2}$} & $0.032^{*}$ & $0.060^{*}$ & $0.038^{*}$ & $0.055^{*}$ & -0.043 & -0.017 & 0.012 & 0.053 \\
\hline & $(0.017)$ & $(0.032)$ & $(0.019)$ & $(0.029)$ & $(0.037)$ & $(0.060)$ & $(0.086)$ & $(0.089)$ \\
\hline minimizer & 12.92 & 8.85 & 12 & 9.21 & - & - & - & - \\
\hline \multirow[t]{2}{*}{ capital } & 0.262 & 0.299 & $0.582^{* * *}$ & $0.228^{* * *}$ & -0.312 & -0.057 & $0.806^{* * *}$ & $0.389^{*}$ \\
\hline & $(0.176)$ & $(0.201)$ & $(0.117)$ & $(0.082)$ & $(0.276)$ & $(0.331)$ & $(0.293)$ & $(0.201)$ \\
\hline \multirow[t]{2}{*}{ capital $^{2}$} & -0.002 & -0.003 & $-0.014^{* * *}$ & -0.003 & 0.004 & 0.002 & $-0.016^{* *}$ & -0.005 \\
\hline & $(0.002)$ & $(0.002)$ & $(0.003)$ & $(0.002)$ & $(0.003)$ & $(0.003)$ & $(0.006)$ & $(0.005)$ \\
\hline Obs. & 722 & 722 & 1444 & 1444 & 87100 & 87100 & 183606 & 183606 \\
\hline \multirow[t]{2}{*}{$\mathrm{R}^{2}$} & 0.67 & 0.62 & 0.46 & 0.41 & 0.34 & 0.08 & 0.29 & 0.09 \\
\hline & Panel B & Estimates & ontrolling $\mathrm{f}$ & r exposure & o IT capi & & & \\
\hline \multirow[t]{2}{*}{ robots } & $-0.824^{* * *}$ & $-1.045^{* * *}$ & $-0.630^{* *}$ & $-1.240^{* * *}$ & -0.370 & -1.106 & -1.325 & $-2.254^{* *}$ \\
\hline & $(0.222)$ & $(0.369)$ & $(0.243)$ & $(0.284)$ & $(0.498)$ & $(0.688)$ & $(0.945)$ & $(0.904)$ \\
\hline \multirow[t]{2}{*}{ robots $^{2}$} & $0.032^{*}$ & 0.058 & 0.021 & $0.077^{* *}$ & -0.039 & 0.020 & 0.012 & 0.099 \\
\hline & $(0.017)$ & $(0.035)$ & $(0.021)$ & $(0.033)$ & $(0.037)$ & $(0.065)$ & $(0.086)$ & $(0.096)$ \\
\hline minimizer & 12.88 & - & - & 8.06 & - & - & - & - \\
\hline \multirow[t]{2}{*}{ IT capital } & 0.207 & $0.282^{* *}$ & $0.229 * * *$ & $0.084^{*}$ & $-0.442^{*}$ & 0.094 & $0.462^{* * *}$ & $0.285^{* *}$ \\
\hline & $(0.124)$ & $(0.131)$ & $(0.065)$ & $(0.043)$ & $(0.228)$ & $(0.242)$ & $(0.153)$ & $(0.116)$ \\
\hline \multirow[t]{2}{*}{ IT capital ${ }^{2}$} & -0.001 & $-0.001^{* *}$ & $-0.001^{* * *}$ & $-0.001^{*}$ & $0.002^{* *}$ & -0.000 & $-0.002^{* *}$ & -0.001 \\
\hline & $(0.000)$ & $(0.000)$ & $(0.000)$ & $(0.000)$ & $(0.001)$ & $(0.001)$ & $(0.001)$ & $(0.001)$ \\
\hline Obs. & 722 & 722 & 1444 & 1444 & 87100 & 87100 & 183606 & 183606 \\
\hline $\mathrm{R}^{2}$ & 0.67 & 0.62 & 0.45 & 0.40 & 0.34 & 0.08 & 0.29 & 0.09 \\
\hline \multicolumn{9}{|c|}{ Panel C. Estimates controlling for exposure to industry value added } \\
\hline \multirow[t]{2}{*}{ robots } & $-0.814^{* * *}$ & $-0.956^{* *}$ & $-0.844^{* * *}$ & $-1.301^{* * *}$ & -0.805 & $-1.274^{*}$ & -1.653 & $-2.425 * *$ \\
\hline & $(0.216)$ & $(0.356)$ & $(0.247)$ & $(0.274)$ & $(0.497)$ & $(0.683)$ & $(1.020)$ & $(0.927)$ \\
\hline \multirow[t]{2}{*}{ robots $^{2}$} & $0.029^{*}$ & 0.044 & 0.028 & $0.075^{* *}$ & -0.010 & 0.036 & 0.019 & 0.103 \\
\hline & $(0.016)$ & $(0.034)$ & $(0.022)$ & $(0.032)$ & $(0.037)$ & $(0.064)$ & $(0.092)$ & $(0.097)$ \\
\hline minimizer & 14.03 & - & - & 8.67 & - & - & - & - \\
\hline \multirow[t]{2}{*}{ industry VA } & $0.074^{* *}$ & $0.057^{* *}$ & $0.130^{* * *}$ & $0.075^{* *}$ & 0.007 & 0.055 & $0.152^{*}$ & $0.100^{*}$ \\
\hline & $(0.030)$ & $(0.025)$ & $(0.043)$ & $(0.032)$ & $(0.047)$ & $(0.050)$ & $(0.087)$ & $(0.052)$ \\
\hline \multirow[t]{2}{*}{ industry $\mathrm{VA}^{2}$} & -0.000 & 0.000 & -0.001 & 0.000 & 0.000 & -0.000 & -0.002 & -0.001 \\
\hline & $(0.000)$ & $(0.000)$ & $(0.001)$ & $(0.001)$ & $(0.001)$ & $(0.001)$ & $(0.002)$ & $(0.002)$ \\
\hline Obs & 722 & 722 & 1444 & 1444 & 87100 & 87100 & 183606 & 183606 \\
\hline $\mathrm{R}^{2}$ & 0.69 & 0.64 & 0.42 & 0.41 & 0.33 & 0.08 & 0.29 & 0.09 \\
\hline \multicolumn{9}{|l|}{ Covariates: } \\
\hline \multicolumn{2}{|l|}{ Time period dummies } & & $\checkmark$ & $\sqrt{ }$ & & & $\sqrt{ }$ & $\sqrt{ }$ \\
\hline $\begin{array}{l}\text { Census divisions and } \\
\text { Baseline covariates }\end{array}$ & $\sqrt{ }$ & $\sqrt{ }$ & $\sqrt{ }$ & $\sqrt{ }$ & $\sqrt{ }$ & $\sqrt{ }$ & $\sqrt{ }$ & $\checkmark$ \\
\hline
\end{tabular}


Table 6: The effects of robots on employment and wages: IV estimates

\begin{tabular}{|c|c|c|c|c|c|c|}
\hline & (1) & (2) & $(3)$ & (4) & $(5)$ & (6) \\
\hline \multicolumn{7}{|c|}{ Panel A. Long-differences, 1990-2007 } \\
\hline US robots & $\begin{array}{c}-1.842^{* * *} \\
(0.664)\end{array}$ & $\begin{array}{c}-2.743^{* * *} \\
(0.669)\end{array}$ & $\begin{array}{c}-2.711^{* * *} \\
(0.658)\end{array}$ & $\begin{array}{c}-3.473^{* *} \\
(1.379)\end{array}$ & $\begin{array}{c}-3.773^{* * *} \\
(1.270)\end{array}$ & $\begin{array}{c}-3.699^{* * *} \\
(1.243)\end{array}$ \\
\hline \multirow[t]{2}{*}{ US robots $^{2}$} & $0.089^{* *}$ & $0.132^{* * *}$ & $0.130^{* * *}$ & $0.149^{*}$ & $0.169^{* *}$ & $0.165^{* *}$ \\
\hline & $(0.037)$ & $(0.036)$ & $(0.036)$ & $(0.076)$ & $(0.068)$ & $(0.067)$ \\
\hline minimizer & 10.34 & 10.39 & 10.42 & 11.65 & 11.17 & 11.20 \\
\hline Obs. & 722 & 722 & 722 & 87100 & 87100 & 87100 \\
\hline First-stage F-statistic & 22.65 & 13.79 & 15.35 & 24.96 & 14.82 & 16.42 \\
\hline \multicolumn{7}{|c|}{ Panel B. Alternative imputation of US data, 1990-2007 } \\
\hline \multirow[t]{2}{*}{ US robots } & $-1.924^{* * *}$ & $-2.865^{* * *}$ & $-2.831^{* * *}$ & $-3.625^{* *}$ & $-3.939^{* * *}$ & $-3.861^{* * *}$ \\
\hline & $(0.694)$ & $(0.699)$ & $(0.687)$ & $(1.442)$ & $(1.328)$ & $(1.299)$ \\
\hline \multirow[t]{2}{*}{$\mathrm{US} \mathrm{robots}^{2}$} & $0.096^{* *}$ & $0.142^{* * *}$ & $0.140^{* * *}$ & $0.161^{*}$ & $0.181^{* *}$ & $0.177^{* *}$ \\
\hline & $(0.039)$ & $(0.039)$ & $(0.038)$ & $(0.082)$ & $(0.073)$ & $(0.072)$ \\
\hline minimizer & 10.02 & 10.08 & 10.11 & 11.26 & 10.88 & 10.91 \\
\hline \multirow{2}{*}{$\begin{array}{c}\text { Obs. } \\
\text { First-stage F-statistic }\end{array}$} & 722 & 722 & 722 & 87100 & 87100 & 87100 \\
\hline & 22.65 & 13.79 & 15.35 & 24.96 & 14.82 & 16.42 \\
\hline & Panel C. Lor & g-difference & , 1990-2014 & & & \\
\hline \multirow[t]{2}{*}{ US robots } & $-1.869^{* * *}$ & $-2.056^{* * *}$ & $-2.067 * * *$ & -2.458 & $-4.188^{* *}$ & $-4.253^{* * *}$ \\
\hline & $(0.459)$ & $(0.674)$ & $(0.654)$ & $(1.514)$ & $(1.656)$ & $(1.548)$ \\
\hline \multirow[t]{2}{*}{$\mathrm{US} \mathrm{robots}^{2}$} & $0.085^{* * *}$ & $0.090 * * *$ & $0.090 * * *$ & 0.065 & $0.153^{*}$ & $0.156^{* *}$ \\
\hline & $(0.023)$ & $(0.032)$ & $(0.031)$ & $(0.074)$ & $(0.079)$ & $(0.074)$ \\
\hline minimizer & 10.99 & 11.42 & 11.48 & - & 13.69 & 13.81 \\
\hline \multirow[t]{2}{*}{ Observations } & 722 & 722 & 722 & 90341 & 90341 & 90341 \\
\hline & 41.28 & 18.94 & 22.74 & 44.53 & 20.01 & 24.07 \\
\hline \multicolumn{7}{|c|}{ Panel D. Long-differences, 2000-2007 } \\
\hline \multirow[t]{2}{*}{ US robots } & $-2.580^{* * *}$ & -0.911 & -0.869 & $-4.847^{* * *}$ & -1.065 & -0.908 \\
\hline & $(0.784)$ & $(0.791)$ & $(0.773)$ & $(1.650)$ & $(2.181)$ & $(2.189)$ \\
\hline \multirow[t]{2}{*}{ US robots ${ }^{2}$} & $0.190^{* * *}$ & 0.031 & 0.026 & $0.337 * *$ & -0.008 & -0.026 \\
\hline & $(0.070)$ & $(0.070)$ & $(0.069)$ & $(0.148)$ & $(0.190)$ & $(0.191)$ \\
\hline minimizer & 6.79 & - & - & 7.19 & - & - \\
\hline \multirow{2}{*}{$\begin{array}{c}\text { Observations } \\
\text { First-stage F-statistic }\end{array}$} & 722 & 722 & 722 & 99319 & 99319 & 99319 \\
\hline & 45.11 & 35.53 & 36.51 & 50.14 & 39.64 & 40.44 \\
\hline & Panel E. Lor & g-difference & $2000-2014$ & & & \\
\hline \multirow[t]{2}{*}{ US robots } & $-2.964^{* * *}$ & $-1.440^{* *}$ & $-1.465^{* *}$ & $-3.271^{* *}$ & $-4.258^{* *}$ & $-4.245^{* *}$ \\
\hline & $(0.621)$ & $(0.585)$ & $(0.579)$ & $(1.531)$ & $(1.947)$ & $(1.920)$ \\
\hline \multirow[t]{2}{*}{ US robots ${ }^{2}$} & $0.183^{* * *}$ & $0.075^{*}$ & $0.077^{* *}$ & 0.122 & 0.183 & 0.181 \\
\hline & $(0.042)$ & $(0.038)$ & $(0.038)$ & $(0.102)$ & $(0.127)$ & $(0.126)$ \\
\hline minimizer & 8.10 & 9.6 & 9.51 & - & - & - \\
\hline Observations & 722 & 722 & 722 & 106375 & 106375 & 106375 \\
\hline First-stage F-statistic & 108.64 & 49.07 & 57.95 & 113.01 & 53.12 & 61.81 \\
\hline Covariates: & & & & & & \\
\hline Division dummies & $\sqrt{ }$ & $\checkmark$ & $\checkmark$ & $\sqrt{ }$ & $\sqrt{ }$ & $\sqrt{ }$ \\
\hline Demographics and industry shares & & $\sqrt{ }$ & $\sqrt{ }$ & & $\sqrt{ }$ & $\sqrt{ }$ \\
\hline Trade, routine jobs & & & $\sqrt{ }$ & & & $\sqrt{ }$ \\
\hline
\end{tabular}

Note: Standard errors that are robust against heteroskedasticity and correlation within states are in parentheses. 
decreases with robotization because the minimizer of the quadratic estimated equation is out-of-the-sample when regressions are done for the period after 2000 (panels D and E), the minimizer is in-the-sample, and thus there is a realistic threshold exposure to robots above which the effect of robotization is positive in both employment and wages.

Acemoglu and Restrepo (2019) also present falsification results according to which the new results highlighted for the post-robotization expansion period were not present in the previous period (e.g. from 1970 to 1990). If the same pattern would arise even before the eve of the robotization era, we might be in the presence of a spurious relationship. We have also performed this exercise (shown in the Appendix, Table B.1). Also in our case, there are no similar pre-trends. Even when there are statistically significant effects, those effects are not in the same shape as the U-shaped relationship highlighted in this article. In fact, we can observe in columns (5) to (7) in Table B.1. an inverted U-shaped relationship between robotization and pre-existing employment evolution within industries.

\section{Conclusion}

Following an influential paper by Acemoglu and Restrepo (2019) that pointed to a generalized negative effect of the introduction of robots in employment and wages in US sectors and commuting zones, we perform a robustness test on those results and uncover a U-shaped relationship in several specifications. In fact, this means that after a given level of robots' penetration within industries, an increase in robotization can indeed lead to increases in employment and wages throughout sectors in the US. We also offer a transitional dynamics explanation for this result: when robots are not adopted, if the productivity of robots is rising more than the productivity of labor is declining, then eventually robots will be adopted in a certain zone where they previously were not used. Then even when robots begin to be adopted, this productivity trend will continue and eventually overtake the displacement effect that implies the negative effect of robots in the labor market.

Our empirical adjustments show that some of the U-shaped relationships occur entirely within the sample, meaning that the rising effect of robots on employment and wages can already be seen in labor markets and those effects are even stronger in other than the automobile industry.

To sum up our results show that some of the more pessimistic views on the effects of robotization may not be verified as the introduction of robots become widespread in the economy. 


\section{A Household problem}

$$
\begin{aligned}
\max _{\left\{X_{c i}, L_{c i}, M_{c i}, K_{c i}\right\}_{i \in \mathcal{I}} L_{c}, M_{c}, K_{c}, Y_{c}, C_{c}, I_{c}} \frac{C_{c}^{1-\psi}-1}{1-\psi}-\frac{B}{1+\varepsilon} L_{c}^{1+\varepsilon} & \\
\text { subject to: } Y_{c}=\left(\sum_{i \in \mathcal{I}} \nu_{i}^{\frac{1}{\sigma}} X_{c i}^{\frac{\sigma-1}{\sigma}}\right)^{\frac{\sigma}{\sigma-1}} & X_{c i}=\alpha^{-\alpha}(1-\alpha)^{-(1-\alpha)} A_{c i}\left[\min \left\{\frac{\gamma_{M} M_{c i}}{\theta_{i}}, \frac{\gamma_{L} L_{c i}}{1-\theta_{i}}\right\}\right]^{\alpha} K_{c i}^{1-\alpha} \\
M_{c} & =D(1+\eta) I_{c}^{\frac{1}{1+\eta}} \\
M_{c} & =\sum_{i \in \mathcal{I}} M_{c i} \\
L_{c} & =\sum_{i \in \mathcal{I}} L_{c i} \\
K_{c} & =\sum_{i \in \mathcal{I}} K_{c i} \\
Y_{c} & =I_{c}+C_{c}
\end{aligned}
$$

The objective function is continuous and strictly concave, while the constraint set is convex and compact, thus ensuring that this maximization problem has a unique solution, which gives us the unique equilibrium of the autarky model.

\section{B Falsification Regressions}


Table B.1: The effects of robots on employment and wages: testing and controlling for pre-trends (1993-2007)

\begin{tabular}{|c|c|c|c|c|c|c|c|c|}
\hline & (1) & $(2)$ & $(3)$ & $(4)$ & $(5)$ & $(6)$ & $(7)$ & $(8)$ \\
\hline \multicolumn{9}{|c|}{ Panel A. Past change in labor market outcomes, 1970-1990 } \\
\hline \multirow[t]{2}{*}{ robots } & -0.358 & -0.172 & 0.061 & -0.652 & $1.664^{*}$ & $1.838^{* *}$ & $3.258^{* * *}$ & 0.271 \\
\hline & $(0.346)$ & $(0.313)$ & $(0.608)$ & $(0.435)$ & $(0.841)$ & $(0.826)$ & $(1.180)$ & $(0.944)$ \\
\hline \multirow[t]{2}{*}{ robots $^{2}$} & 0.027 & 0.014 & -0.028 & 0.045 & $-0.123^{* *}$ & $-0.134^{* *}$ & $-0.341 * * *$ & -0.038 \\
\hline & $(0.025)$ & $(0.022)$ & $(0.078)$ & $(0.037)$ & $(0.057)$ & $(0.056)$ & $(0.125)$ & $(0.081)$ \\
\hline Observations & 722 & 722 & 712 & 722 & 59230 & 59230 & 58402 & 59230 \\
\hline $\mathrm{R}^{2}$ & 0.42 & 0.44 & 0.44 & 0.32 & 0.50 & 0.50 & 0.49 & 0.30 \\
\hline \multicolumn{9}{|c|}{ Panel B. Estimates controlling for exposure to industry trends between 1970 and 1990} \\
\hline \multirow[t]{2}{*}{ robots } & $-0.572^{* *}$ & $-0.589^{* *}$ & -0.736 & -0.595 & -0.409 & -0.423 & -1.063 & -0.483 \\
\hline & $(0.242)$ & $(0.230)$ & $(0.509)$ & $(0.360)$ & $(0.529)$ & $(0.516)$ & $(1.075)$ & $(0.715)$ \\
\hline \multirow[t]{2}{*}{ robots $^{2}$} & 0.014 & 0.015 & 0.033 & 0.021 & -0.034 & -0.034 & 0.061 & -0.025 \\
\hline & $(0.018)$ & $(0.018)$ & $(0.075)$ & $(0.035)$ & $(0.039)$ & $(0.038)$ & $(0.136)$ & $(0.066)$ \\
\hline \multirow[t]{2}{*}{ industry trends } & $-0.036^{*}$ & $-0.036^{*}$ & $-0.034^{*}$ & $-0.060 * * *$ & $-0.076^{* *}$ & $-0.077^{* *}$ & $-0.070^{*}$ & $-0.119 * * *$ \\
\hline & $(0.020)$ & $(0.019)$ & $(0.020)$ & $(0.018)$ & $(0.035)$ & $(0.035)$ & $(0.036)$ & $(0.035)$ \\
\hline Obs & 722 & 722 & 712 & 722 & 87100 & 87100 & 85776 & 87100 \\
\hline 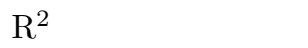 & 0.67 & 0.67 & 0.66 & 0.63 & 0.33 & 0.33 & 0.33 & 0.08 \\
\hline \multicolumn{9}{|l|}{ 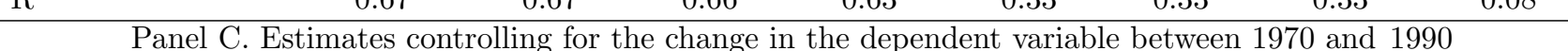 } \\
\hline \multirow[t]{2}{*}{ robots } & $-0.772^{* * *}$ & $-0.788^{* * *}$ & $-1.095^{* *}$ & $-1.164^{* * *}$ & -0.753 & -0.760 & -1.671 & $-1.336^{* *}$ \\
\hline & $(0.216)$ & $(0.204)$ & $(0.424)$ & $(0.366)$ & $(0.535)$ & $(0.526)$ & $(1.043)$ & $(0.608)$ \\
\hline \multirow[t]{2}{*}{$\operatorname{robots}^{2}$} & $0.029^{*}$ & $0.029^{*}$ & 0.071 & $0.068^{*}$ & -0.013 & -0.013 & 0.123 & 0.020 \\
\hline & $(0.016)$ & $(0.015)$ & $(0.065)$ & $(0.036)$ & $(0.038)$ & $(0.038)$ & $(0.137)$ & $(0.058)$ \\
\hline Obs & 722 & 722 & 712 & 722 & 55988 & 55988 & 55182 & 55988 \\
\hline $\mathrm{R}^{2}$ & 0.66 & 0.67 & 0.66 & 0.63 & 0.41 & 0.41 & 0.40 & 0.16 \\
\hline \multicolumn{9}{|l|}{ Covariates: } \\
\hline Census divisions & $\checkmark$ & $\sqrt{ }$ & $\sqrt{ }$ & $\sqrt{ }$ & $\sqrt{ }$ & $\sqrt{ }$ & $\sqrt{ }$ & $\sqrt{ }$ \\
\hline $\begin{array}{l}\text { Demographics and } \\
\text { Industry shares }\end{array}$ & $\sqrt{ }$ & $\sqrt{ }$ & $\sqrt{ }$ & $\checkmark$ & $\checkmark$ & $\sqrt{ }$ & $\sqrt{ }$ & $\sqrt{ }$ \\
\hline Trade, routine jobs & & $\sqrt{ }$ & $\sqrt{ }$ & $\sqrt{ }$ & & $\sqrt{ }$ & $\sqrt{ }$ & $\sqrt{ }$ \\
\hline
\end{tabular}

Note: Standard errors that are robust against heteroskedasticity and correlation within states are in parentheses. 


\section{References}

Acemoglu, D., Lelarge, C., and Restrepo, P. (2020). Competing with robots: Firm-level evidence from France. American Economic Review Papers and Proceedings, forthcoming.

Acemoglu, D. and Restrepo, P. (2019). Robots and jobs: Evidence from US labor markets. Journal of Political Economy, forthcoming.

Acemoglu, D. and Restrepo, P. (2020). The wrong kind of AI? artificial intelligence and the future of labour demand. Cambridge Journal of Regions, Economy and Society, forthcoming.

Artuc, E., Bastos, P., and Rijkers, B. (2018). Robots, tasks and trade. Policy Research working paper; no. WPS 8674 .

Autor, D. H., Levy, F., and Murnane, R. J. (2003). The skill content of recent technological change: An empirical exploration. The Quarterly Journal of Economics, 118(4):1279-1333.

Brynjolfsson, E. and McAfee, A. (2014). The second machine age: Work, progress, and prosperity in a time of brilliant technologies. W. W. Norton Company.

Ford, M. (2015). The rise of the robots. Basic Books, New York.

Goos, M. and Manning, A. (2007). Lousy and lovely jobs: The rising polarization of work in Britain. The Review of Economics and Statistics, 89(1):118-133.

Graetz, G. and Michaels, G. (2018). Robots at work. Review of Economics and Statistics, 100(5):753-768.

Guimarães, L. and Gil, P. (2019). Explaining the labor share: Automation vs labor market institutions. Economics Working Papers 19-01, Queen's Management School, Queen's University Belfast.

Leigh, N. G. and Kraft, B. R. (2018). Emerging robotic regions in the United States: Insights for regional economic evolution. Regional Studies, 52(6):804-815.

Michaels, G., Natraj, A., and Van Reenen, J. (2014). Has ICT polarized skill demand? evidence from eleven countries over twenty-five years. Review of Economics and Statistics, 96(1):60-77.

Tolbert, C. M. and Sizer, M. (1996). US commuting zones and labor market areas: A 1990 update. Economic Research Service Staff Paper 9614. 